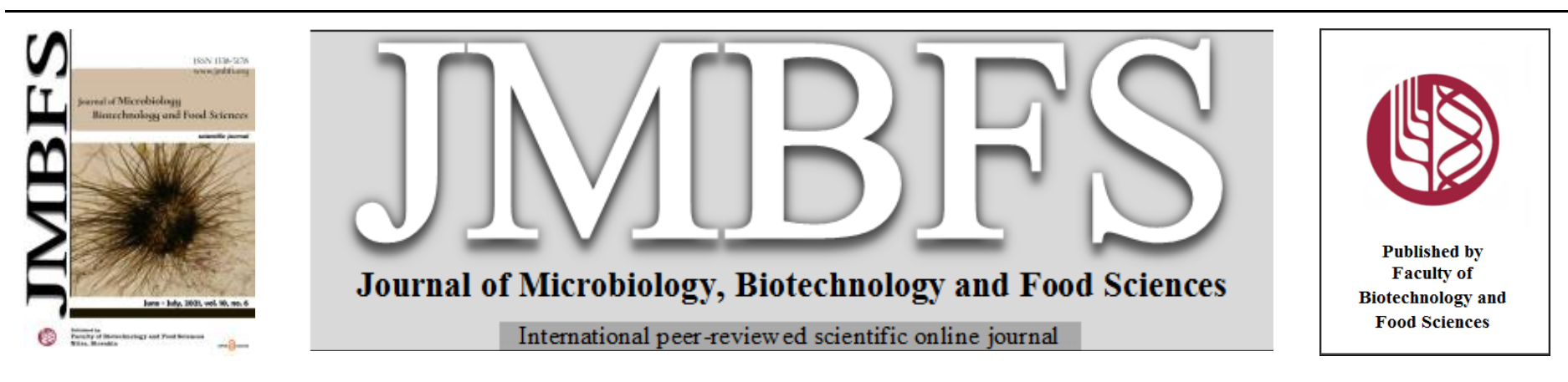

\title{
CHARACTERIZATION OF WHITE SESAME SEED OIL AND ITS BIOACTIVE COMPONENTS
}

\section{Farhan Aslam $^{1}$, Sanaullah Iqbal ${ }^{*}$, Muhammad Imran $^{2}$, Aftab Ahmad Anjum ${ }^{3}$, Syed Amir Gilani ${ }^{2}$, Zubair Farooq ${ }^{1}$, Hafiza Bushra Tariq $^{4}$, Sergei Terentev ${ }^{5}$, Anna Terekhova ${ }^{6}$, Mohammad Ali Shariati ${ }^{6, *}$}

\begin{abstract}
Address(es):
${ }_{1}^{1}$ Department of Food Science and Human Nutrition, University of Veterinary and Animal Sciences, Lahore Syed Abdul Qadir Jillani (Out Fall) Road, Lahore Pakistan.

${ }^{2}$ University Institute of Diet and Nutritional Sciences, Faculty of Allied Health Sciences, The University of Lahore-Lahore, Pakistan.

${ }^{3}$ Department of Microbiology, University of Veterinary and Animal Sciences, Lahore Syed Abdul Qadir Jillani (Out Fall) Road, Lahore - Pakistan.

${ }^{4}$ Institute of Agricultural Sciences, University of the Punjab Lahore- Pakistan.

${ }^{5}$ Smolensk State Agricultural Academy, Smolensk, Russian Federation.

${ }^{6}$ K.G. Razumovsky Moscow State University of technologies and management (the First Cossack University), Moscow, Russian Federation.

*Corresponding author: sanaullah.iqbal@uvas.edu.pk, Shariatymohammadali@gmail.com

https://doi.org/10.15414/jmbfs.4641

ARTICLE INFO

Received 15. 9. 2020

Revised 30. 12. 2020

Accepted 5. 1. 2021

Published 1. 6. 2021

Regular article

open $\partial_{\text {AcCESS }}$

ABSTRACT

The purpose of this study was to evaluate the physicochemical properties of white sesame seed oil (WSSO) (PB-Till 90) along with their bioactive components. Among physicochemical properties; free fatty acids $(0.95 \pm 0.05 \%)$, peroxide value $(0.88 \pm 0.03 \mathrm{meq} / \mathrm{kg})$, thiobarbituric acid value $(0.045 \pm 0.0 \mathrm{mg}$ malonaldehyde/ $\mathrm{kg}$-oil), free radical scavenging activity (DPPH) $(85.07 \pm 0.01 \%)$, and iodine value $(113.4 \pm 1.46 \mathrm{~g} / 100 \mathrm{gm})$ were observed. Fatty acid (\%) profile, determined by gas chromatography, mostly comprised of unsaturated fatty acids. Bioactive components were determined using HPLC and include tocopherol $\mathrm{mg} / \mathrm{kg}(\alpha 8.12 \pm 0.0, \delta 23.98 \pm 0.02$, $\gamma 3.125 \pm 0.01$ ), polyphenol $\mathrm{mg} / \mathrm{kg}$ (Gallic acid $0.985 \pm 0.001$, protocatechuic acid $0.018 \pm 0.001$, syringic acid $0.024 \pm 0.002$, ferulic acid $0.134 \pm 0.001$ ), stigmasterol $6689.34 \pm 0.02$ and lignans $\mathrm{mg} / \mathrm{kg}$ (sesamin $18340 \pm 8.5$, sesamolin $28340 \pm 13.7$ and sesamol $224 \pm$ 2.0) were quantified. The results show that WSSO from variety PB-Till 90 has good physicochemical properties and contain appreciable quantities of bioactive components to make its usage as a functional food ingredient.
\end{abstract}

Keywords: Bioactive components, Fatty acid profile, Physicochemical properties, Sesame oil

\section{INTRODUCTION}

As a result of research interventions, the concept of nutraceutical and functional foods has flourished. Now, consumers have started to look at food not only for its basic nutrients but also for its health benefits. Now it's the responsibility of nutritionists and researchers to emphasize their concentration towards health claims and safety issues of new foods. The major emphasis of these foods is on recuperating health and minimizing disease threat mainly through prevention. White sesame (Sesamum indicum) has its origin in India and roots in the history from more than 5000 years ago, belongs to the family Pedaliaceae and is considered as among one of the oldest crops on the planet (Bisht et al., 1998).

Sesame has given the name of "queen" of oil seed crops because of the superb quality of the consumable oil it produces (Akinoso et al., 2010). It serves as a healthy food for humans because of its elevated level of superior quality oil that ranges between 42-54\% (Orruño and Morgan, 2007). Sesame seed flour contains carbohydrates (5-9\%), protein (19-25\%), fiber (3-5\%) and some minerals such as calcium, phosphorous in abundance and vitamin $\mathrm{E}$ (Weiss, 2000). Sesame oil is a good source of unsaturated fatty acids which are approximately $80 \%$ with $37.2 \%$ of the oleic and $46.3 \%$ of the linoleic acids (Weiss, 2000). Sesame seed contains very high levels (up to $2.5 \%$ ) of furofuran lignans (mainly Sesamin, sesamolin, and sesaminol glucosides) with beneficial physiological activities (Uzun et al., 2008). Bioactive components in sesame seed oil show positive effects against chronic diseases like blood pressure, lipid profile and hyperglycemia (Jannat $\boldsymbol{e t}$ al., 2010). Sesame seed lignans (Sesamin and sesamolin) reported to have various health benefits including modulation of fatty acid metabolism, cholesterol lowering effect through inhibition in absorption and biosynthesis, antioxidant and vitamin E sparing effects, hypotensive effects and anti-aging effects (Hirata et al., 1996). Both these lignans show significant results against hypertension in humans by lowering the intestinal absorption of cholesterol, this effect is mainly due to sesamin that is enhanced by $\alpha$ - tocopherol (Ogawa et $\boldsymbol{a l}$., 1995). Its consumption significantly increased the level of vitamin $\mathrm{E}$ in animals and helps to reduce the oxidative stress (Kamal-Eldin et al., 1995; Yamashita et al., 1992). Diabetes, migraines and hepatitis like chronic diseases have been treated with sesame seed oil in the recent years (Anilkumar et al., 2010). The lower quantity of saturated fat and higher quantity of monounsaturated and polyunsaturated fatty acids (PUFA) makes the white sesame seed oil (WSSO) suitable for daily consumption. On the other hand, sesamin and sesamolin are the major phenolic lignans found in sesame oil ranges from 1.0-2.0\% (Reshma et al., 2010) and these have proven beneficial effects as they serve as an antioxidant, antihypertensive, antimutagenic, anti-inflammatory and antithrombotic and cardioprotective effects (Kaneez et al., 2007). White sesame variety PB Till-90 is one of the important and majorly grown sesame variety in Pakistan and has not been characterized especially for its nutritional value and other health benefits in detail. It is the reason that sesame oil utilization is not much in our routine life. Sesame seed oil is among one of the few vegetable oils that can directly be used without refining. The stability of sesame seed oil is due to the presence of bioactive components in it like sesamin, sesamolin, sesamol and tocopherols (Chang et al., 2002). Its healthy aspects make it suitable to be used in different products and as a whole natural salad oil. The purpose of the study was to evaluate the WSSO for physico-chemical properties, fatty acid profile and bioactive components like tocopherol, polyphenol, phytosterol and lignans.

\section{Scientific hypothesis}

The scientific hypothesis of this study is mainly determined the chemical profiling, fatty acid composition of extracted white sesame oil along with their antioxidant potential. Further, by conducting these analyses which is used to enhance the biological value and also used to prepare the different quality products through white sesame oil. 


\section{MATERIAL AND METHODS}

\section{Materials, chemicals, standards and reagents}

White sesame was procured from Ayub Agriculture Research Institute Faisalabad, Pakistan. All chemicals, reagents, solvents and standards for bioactive components were of highest purity for laboratory analysis and were purchased from Sigma Aldrich-UK.

WSSO Extraction and Characterization

The WSSO was extracted from PB Till-90 seeds by solvent extraction method (Latif and Anwar, 2011) using n-hexane as organic solvent. After extraction by Soxhlet apparatus, oil was tested for various physical and chemical attributes including color, refractive index, specific gravity, smoke point and chemica characteristics like free fatty acids, peroxide value, thiobarbituric acid (TBA) acid value, iodine value, saponification value, unsaponifiable material and free radical scavenging activity by following the procedures described in AOAC. (2003).

\section{DPPH free radical scavenging activity}

Free radical scavenging activity was measured using 1,1-diphenyl-2 picrylhydrazyl (DPPH), by adopting the method described by Bozin, MimicaDukic, Simin, and Anackov (2006). The absorbance was measured at $515 \mathrm{~nm}$ against blank. The percentage of radical scavenging activity (RSA) was calculated using the following equation:

$$
\operatorname{RSA}(\%)=\frac{A_{0}-A_{s}}{A_{S}} \times 100
$$

$A_{0}$ is the absorbance of control and $A_{s}$ is the absorbance of the sample at $515 \mathrm{~nm}$.

\section{Polyphenols}

Polyphenols in sesame seed oil were determined by adopting the procedure of Ixtaina et al. (2011). The residues were dissolved in acetonitrile and $10 \%$ acetic acid (50:50) and were analyzed by HPLC/APCI-MS. The chromatographic separations were performed with column C18 (150 mm X $2.1 \mathrm{~mm}) 335 \mu \mathrm{m}$ Xterra (Waters) and guard column C18 (4mm X $2 \mathrm{~mm}$ ) (Phenomenex, Cheshire, $\mathrm{UK})$.

\section{Fatty Acid Profile}

Fatty acid methyl esters (FAMEs) of sesame seed oil were prepared using the standard IUPAC method (IUPAC, 1987) as described by Latif and Anwar (2011). Fatty acid methyl esters were then analyzed against standards (Sigma Aldrich-UK) by gas chromatograph (model: 14-A, Shimadzu, Japan) using polar capillary column (SP-2330, 30m x $0.32 \mathrm{~mm}$ ) coated with methyl lignose, flame ionization detector and nitrogen gas as a carrier.

\section{Tocopherols}

The tocopherols $(\alpha, \gamma$, and $\delta$ ) were determined in sesame seed oil using High Performance Liquid Chromatography on UV detector at $295 \mathrm{~nm}$ following method explained by Latif and Anwar (2011).

\section{Phytosterol}

Sample preparation and analysis of phytosterols were performed by adopting the method of Ryan, Galvin, Connor, Maguire, and O'Brien (2006) with some modifications. The sample was loaded onto a column Luna C8 (2) (250 x 4.6 $\mathrm{mm}$ ) Phenomenex, Cheshire, UK. All determinations were done at $205 \mathrm{~nm}$ for phytosterols.

\section{Lignans (Sesamin \& Sesamolin)}

Lignans (sesamin and sesamolin) were analyzed by adopting the method of Schwertner and Rios (2012) with little modifications. The sample was injected into the HPLC (Model: Perkin Elmer series 200 USA) equipped with C18 $(4.6 \mathrm{~mm} \times 150 \mathrm{~mm})$. The UV detector was set at $288 \mathrm{~nm}$. Sesamin, sesamolin and sesamol were quantified by comparing with standards Sigma Aldrich-UK.

\section{RESULTS AND DISCUSSION}

The physicochemical properties of crude WSSO are presented in Table 1. Colour of oil ranges from clear yellowish to slightly red, with results of $18.4 \pm 0.2$ yellow and $1.53 \pm 0.153$ red. Refractive index gives us an idea about rancidity and adulteration, the refractive index of sesame seed oil was $(1.4598 \pm 0.1)$, previously in an Indian variety it was reported 1.469 by Alyemeni et al. (2011) specific gravity is the ratio of density of a substance to the reference substance; water was the reference substance to measure the specific gravity. Sesame seed oil specific gravity was $(0.9210 \pm 0.0)$, the point at which the oil starts to burn is the smoke point, white sesame seed oil smoke point was $184 \pm 3{ }^{\circ} \mathrm{C}$. The free fatty acid is the \% age of oleic acid in the oil that indicated the oxidation level of lipids, it is directly related to acidic composition of oil, sesame seed oil free fatty acid value was $(0.95 \pm 0.05 \%)$.

\begin{tabular}{|c|c|c|}
\hline $\begin{array}{l}\text { Serial } \\
\text { no. }\end{array}$ & Physico-chemical Characteristics & Results \\
\hline 1 & Colour Red & $1.53 \pm 0.153$ \\
\hline 2 & Colour Yellow & $18.4 \pm 0.2$ \\
\hline 3 & Refractive Index & $1.4598 \pm 0.1$ \\
\hline 4 & Specific Gravity $\left(\mathrm{g} / \mathrm{cm}^{3}\right)$ & $0.921 \pm 0.0$ \\
\hline 5 & Smoke Point ${ }^{\circ} \mathrm{C}$ & $184 \pm 3$ \\
\hline 6 & Free Fatty Acid \% & $0.95 \pm 0.05$ \\
\hline 7 & Peroxide Value (meq/kg) & $0.88 \pm 0.03$ \\
\hline 8 & $\begin{array}{l}\text { Thiobarbituric Acid Value (mg } \\
\text { malonaldehyde/kg-oil) }\end{array}$ & $0.045 \pm 0.0$ \\
\hline 9 & Iodine Value $\%$ or $\mathrm{g} / 100 \mathrm{gm}$ & $113.4 \pm 1.46$ \\
\hline 10 & Saponification Value $(\mathrm{mg} \mathrm{KoH} / \mathrm{g})$ & $189.7 \pm 3.97$ \\
\hline 11 & Unsaponifiable Matter \% & $1.44 \pm 0.03$ \\
\hline 12 & Free Radical Scavenging Activity \% & $85.07 \pm 0.01$ \\
\hline
\end{tabular}

The measurement of resistance against oxidation is the peroxide value, WSSO peroxide value was $(0.88 \pm 0.03 \mathrm{meq} / \mathrm{kg})$ while thiobarbituric acid value is an important indicator of the oil quality because it tells about the rancidity of oil, sesame seed oil thiobarbituric acid value was $(0.045 \pm 0.0 \mathrm{mg}$ malonaldehyde $/ \mathrm{kg}$ oil). The iodine value is the measurement of degree of unsaturation of fatty acids, higher value of iodine value shows that it is a semi dried oil and unsuitable to be used in paint industry before dehydration (Fernando and Akujobi, 1987). Iodine value of WSSO was $(113.4 \pm 1.46 \mathrm{~g} / 100 \mathrm{~g})$, in one of the studies it was $107 \mathrm{~g}$ of $\mathrm{I} / 100 \mathrm{gm}$, free radical scavenging activity (DPPH) is the measurement of inhibition of linoleic acid peroxidation, sesame seed oil (PB Till-90) showed DPPH activity as $85.07 \%$, previously in one of the studies it was $62.2 \mu \mathrm{g} / \mathrm{ml}$, saponification value is the measurement of chain length of fatty acids presents in it, higher proportion of it make it unsuitable to be used in soap industry, sesame seed oil saponification value was $189.7 \pm 3.97 \mathrm{mg} \mathrm{KoH} / \mathrm{g}$, in one of the studies it was $169 \mathrm{mg}$ of $\mathrm{KOH} / \mathrm{g}$ of oil reported by (Latif and Anwar, 2011), unsaponifiable matter is the components in oil that fail to form soap, in our study it was $1.44 \pm 0.03 \%$.

\section{Fatty Acid Profile}

Fatty acid profile of white sesame seed oil (PB Till-90) is shown in Table 2. The WSSO fatty acid profile includes capric acid C10:0 (10.9), lauric acid C12:0 (2.3), myristic acid C14:0 (2.9), myristoleic acid C14:1 (10.9), palmitic acid C16:0 (19.9), palmitoleic acid C16:1 (1.3), heptadecanoic acid C17:0 (1.9), stearic acid C18:0 (13.4), oleic acid C18:1 (11.4), linoleic acid C18:2 (12.9) and linolenic acid C18:3, (11.7). The major portion of present sesame seed oil comprised of PUFA i.e. $36.5 \%$ having oleic, linoleic and linolenic acids which are considered to be important in prevention of cardiovascular diseases (Virtanen et al., 2018). It is surprising that some sesame varieties contain saturated fatty acids (Table 2) especially myristic, palmitic and caprylic acid as major portion (Asghar and Majeed, 2013) while others have more unsaturated fatty acids (oleic and linoleic acids) even up to $85 \%$ not only in Pakistan (Latif and Anwar, 2011) but in some sesame varieties in Congo as well (Nzikou et al. 2009). This composition makes some Pakistani varieties like PB-Till 90 more suitable for industrial applications due to more stability at high temperatures. It is also fact that palmitic and myristic acids are the fatty acids that raise the cholesterol level in consumer as reported by Zock et al. (1994). In PB Till-90 major saturated fatty acids found were palmitic acid and stearic acid. Similar results for fatty acid profile of sesame seed have been reported in previous studies (Asghar et al., 2013; Nzikou et al., 2009).

\section{Bioactive Components}

Results for bioactive components in sesame variety PB-Till 90 are presented in Table 3 Tocopherol contents in sesame seed oil were $(\alpha 8.12 \mathrm{mg} / \mathrm{kg}, \delta 23.98 \pm$ $0.02 \mathrm{mg} / \mathrm{kg}, \gamma 3.125 \pm 0.01 \mathrm{mg} / \mathrm{kg}$ ), while sesamin and sesamolin were the major fat soluble lignans, sesamin $18340 \mathrm{mg} / \mathrm{kg}$, sesamolin $28340 \mathrm{mg} / \mathrm{kg}$ and sesamol $224 \mathrm{mg} / \mathrm{kg}$ (Table 3). The most important oil sources for lignans are flaxseed and sesame seed oils (Peterson et al., 2010; Reshma et al., 2010) and it is evident from several studies that they play very important role in management of cardiovascular diseases (Peterson et al., 2010). It is the reason that severa efforts have been done to improve the extraction process of lignans from edible oil sources (Latif and Anwar, 2011; Reshma et al., 2010). The present sesame variety i.e. PB Till-90 is an excellent source of sesamin and sesamolin. Higher contents of tocopherol in oil increase the oxidative stability of the oil. Latif and Anwar (2011) reported tocopherol levels as $\alpha 2.4 \mathrm{mg} / \mathrm{kg}, \gamma 578 \mathrm{mg} / \mathrm{kg}, \delta 3.7$ $\mathrm{mg} / \mathrm{kg}$ using solvent extraction method and it can be improved using enzyme- 
assisted extraction. PB Till-90 polyphenol contents were Gallic acid $0.985 \pm$ $0.001 \mathrm{mg} / \mathrm{kg}$, protocatechuic acid $0.018 \pm 0.001 \mathrm{mg} / \mathrm{kg}$, syringic acid $0.024 \pm$ $0.002 \mathrm{mg} / \mathrm{kg}$ and ferulic acid $0.134 \pm 0.001 \mathrm{mg} / \mathrm{kg}$. The presence of polyphenols was supported by the studies of Borchani et al. (2010), they reported polyphenols as $14.21 \mathrm{mg}$ cafeic acid kg-1 of the raw sesame oil. Presence of polyphenols also enhance the antioxidant activity.

Table 2 Fatty acid profile of sesame seed oil PB Till-90

\begin{tabular}{llc}
$\begin{array}{l}\text { Serial } \\
\text { no. }\end{array}$ & Fatty Acids & Results (\%) \\
\hline 1 & Caprylic Acid (C:8:0) & ND \\
2 & Capric Acid (C:10:0) & 10.9 \\
3 & Lauric Acid (C:12:0) & 2.3 \\
4 & Myristic Acid (C:14:0) & 2.9 \\
5 & Myristoleic Acid (C:14:1) & 10.1 \\
6 & Eicosanoic Acid (C:20:0) & ND \\
7 & Elaidic Acid (C:18:1) & 19.9 \\
8 & Palmitic Acid (C:16:0) & 1.3 \\
9 & Palmitoleic Acid (C16:1) & ND \\
10 & Pentadecanoic Acid (C:15:0) & 1.9 \\
11 & Heptadecanoic Acid (C:17:0) & 11.4 \\
12 & Stearic Acid (C18:0) & 12.9 \\
13 & Oleic Acid (C:18:1) & 11.7 \\
14 & Linoleic Acid (C:18:2) & ND \\
15 & Linolenic Acid(C:18:3) & ND \\
16 & Erucic Acid (C:22:1) & \\
17 & Behenic Acid (C:20:1) & \\
\hline
\end{tabular}

ND; Not detected

Table 3 Bioactive Components in sesame seed oil PB Till-90

\begin{tabular}{llcc}
\hline Serial no. & Components & Description & $\begin{array}{c}\text { Results } \\
(\mathbf{m g} / \mathbf{k g})\end{array}$ \\
\hline \multirow{3}{*}{1} & \multirow{3}{*}{ Tocopherols } & Aplha $(\alpha)$ & $8.12 \pm 0.0$ \\
& & Sigma $(\delta)$ & $23.98 \pm 0.02$ \\
& & Gamma (y) & $3.125 \pm 0.01$ \\
& & Gallic Acid & $0.985 \pm 0.001$ \\
2 & Polyphenols & Protocatechuic acid & $0.018 \pm 0.001$ \\
& & Syringic acid & $0.024 \pm 0.002$ \\
3 & Phytosterols & Ferrulic acid & $0.134 \pm 0.001$ \\
& & Stigma Sterol & $6689.34 \pm 0.02$ \\
4 & Lignans & Sesamin & $18340 \pm 8.5$ \\
& & Sesamolin & $28340 \pm 13.7$ \\
& & Sesamol & $2240 \pm 2.0$ \\
\hline
\end{tabular}

Phytosterols, primarily $\beta$-sitosterol, campesterol and stigmasterol, are membrane constituents of plants that effectively reduce serum LDL cholesterol and atherosclerotic risk (De Jong $\boldsymbol{e t}$ al., 2003). In our study stigmasterol was detected in the sesame seed oil that was $6689.34 \pm 0.02 \mathrm{mg} / \mathrm{kg}$. The presence of phytosterol was also supported by Ryan et al. (2007) and they detected stigmasterol content in sesame oil as $41.5 \mathrm{mg} / 100 \mathrm{gm}$. Lignans (sesamin, sesamolin and sesamol) are the oxidative coupling product of $\beta$ hydroxyphenylpropane (Fukuda et al., 1986). These compounds increase the oxidative stability of the oil. Sesame seed oil has sufficient quantities of fat soluble lignans (Schwertner \& Rios, 2012). It is cleared from the results that WSSO PB-Till 90 characterization and especially the presence of sufficient quantities of components like tocopherol, polyphenol, phytosterol and lignans make sesame seed oil distinguished from other vegetable oils and make it suitable for human consumption.

\section{Strengths}

No other study for the characterization that includes physicochemical properties, fatty acid profile and evaluation of bioactive components of white sesame seed oil PB Till-90 has conducted. GC/MS and HPLC techniques were used for the evaluation of fatty acid profile and bioactive components, respectively.

\section{Conclusion and Future Directions}

Physicochemical properties and bioactive components of sesame seed oil are unique. The results of characterization and the presence of bioactive components make it suitable for human consumption. The presence of MUFA and PUFA makes it a good replacement for other vegetable oils. All these properties make it suitable not only for human consumption but also to be used in food industry, the pharmaceutical industry and in cosmetics preparation. Comparison with other varieties of sesame seeds and other vegetable oils will give good comparison to highlight its different aspects.

Acknowledgement /Research Funding: This work was supported by the Higher Education Commission, Islamabad under Indigenous PhD Fellowship for 5000 Scholars (Phase-II) to Farhan Aslam.

\section{REFERENCES}

Akinoso, R., Aboaba, S. A. \& Olayanju, T.M.A. 2010. Effect of moisture content and heat treatment on peroxide value and oxidative stability of unrefined sesame oil. Af J Food Agricul Nut Develop, 10(10), 4268-4285.

Alyemeni, M.N., Basahy, A.Y. \& Sher, H. 2011. Physico-chemical analysis and mineral composition of some sesame seeds (Sesamum Indicum L.) grown in Gizan area of Saudi Arabia. J Med Plants Res, 5(2), 270-274.

Anilkumar, K.R., Pal, A., Khanum, F. \& Bawa, A.S. (2010). Nutritional, medicinal and industrial use of sesame (Sesamum indicum L.) seeds-an overview. Agriculturae. Conspectus Sci, 75(4), 159-168.

AOAC. (2003). Official Methods of Analysis of Association of Official Analytical Chemists International (17th ed.). VA, USA: In: Horwitz, W. AOAC Press Arlington.

Asghar, A., \& Majeed, M.N. (2013). Chemical characterization and fatty acid profile of different sesame verities in Pakistan. Am J Sci Indus Res, 4(6), 540 545. https://10.5251/ajsir.2013.4.6.540.545

Bisht, I.S., Mahajan, R., Loknathan, T.R. \& Agrawal, R.C. (1998). Diversity in Indian sesame collection and stratification of germplasm accessions in different diversity groups. Genetic Resour Crop Evol, 45(4), 325-335.

Borchani, C., Besbes, S., Blecker, C. \& Attia, H. 2010. Chemical characteristics and oxidative stability of sesame seed, sesame paste and olive oils. J Agricul Sci Technol, 12, 585-596.

Bozin, B., Mimica-Dukic, N., Simin, N. \& Anackov, G. (2006). Characterization of the volatile composition of essential oil of some Lamiaceae species and the antimicrobial and antioxidant activities of the entire oils. J Agricul Food Chem, 54, 1822-1828. https://doi.org/10.1021/jf051922u

Chang, L.W., Yen, W.J., Huang, S.C. \& Duh, P.D. (2002). Antioxidant activity of sesame coat. Food Chem, 78, 347-354. https://doi.org/10.1016/s0308 $\underline{\text { 8146(02)00119-X }}$

De Jong, N., Plat, J., \& Mensink, R. P. (2003). Metabolic effects of plant sterols and stanols. $J$ Nut Biochem, 4, 362-369. https://doi.org/10.1016/s09552863(03)00002-0

Fernando, C.E.C., \& Akujobi, E.O. (1987). Chemical Analysis of Selected vegetable oils and fats of Sokoto State of Nigeria. J Basic Appl Sci, 1(11).

Fukuda, Y., Isobe, M., Nagata, M., Osawa, T., \& Namiki, M. (1986). Acidic Transformation of Sesamolin, the Sesami-oil Constituent, into an Antioxidant Bisepoxylignan, Sesaminol. Heterocycles, 24(4), 923-926. https://doi.org/10.3987/R-1986-04-0923

Hirata, F., Fujita, K. \& Ishikura, Y. 1996. Hypocholesterolemic effect of sesame lignan in humans. Atherosclerosis, 122(1), 135-136.

IUPAC. (1987). Standard methods for the analysis of oils, fats and derivatives (C. P. a. A. Hautfenne Ed. 7th ed.). London: Blackwell Scientific Publications.

Ixtaina, V.Y., Martínez, M.L., Spotorno, V., Mateo, C.M., Maestri, D.M., Diehl, B.W.K. \& Tomás, M.C. (2011). Characterization of chia seed oils obtained by pressing and solvent extraction. J Food Com Anal, 24(2), 166-174 https://doi.org/10.1016/j.jfca.2010.08.006

Jannat, B., Oveisi, M.R., Sadeghi, N., Hajimahmoodi, M., Behzad, M., Choopankari, E. \& Behfar, A.A. (2010). Effect of roasting temperature and time on healthy nutraceuticals of antioxidants and total phenolic content in Iranian sesame seeds (Sesamum indicum L.). Ir J Environ Health Sci Eng, 7(1), 97-102.

Kamal-Eldin, A., Pettersson, D., \& Appelqvist L.A. (1995). Sesamin (a compound from sesame oil) increases tocopherol levels in rats fed ad libitum. Lipids, 30(6): 499-505. https://doi.org/10.1007/BF02537023

Kaneez, F.S., Al-Salam, S. \& Alaaeldin, A.H. (2007). Sesame oil as a protective agent against doxorubicin-induced cardiotoxicity in rat. Am J Pharmacol Toxicol, 2(4), 159-163. https://doi.org/10.3844/ajptsp.2007.159.163

Latif, S., \& Anwar, S. (2011). Aqueous enzymatic sesame oil and protein extraction. Food Chem, 125, 679-684 https://doi.org/10.1016/j.foodchem.2010.09.064

Nzikou, M., Matos, L., Bouanga, G.K., Kalou, N., C.B., , Pambou, N.P.G., Kimbonguila, A. \& Desobry, S. 2009. Chemical composition of the seeds and oil of sesame (Sesamum indicum L.) grown in Congo-Brazzaville. Ad J Food Sci Technol, 1, 6-11.

Ogawa, H., Sasagawa, S., Murakami, T. \& Yoshizumi, H. (1995). Sesame lignans modulate cholesterol metabolism in the stroke-prone spontaneously hypertensive rat. Clin Exp Pharmacol Physiol Suppl, 22(1), 310-312. https://doi.org/10.1111/j.1440-1681.1995.tb02932.x

Orruño, E. \& Morgan, M.R.A. 2007. Purification and characterization of the 7S globulin storage protein from sesame (Sesamum indicum L.). Food Chem, 100, 926-934. https://doi.org/10.1016/j.foodchem.2005.10.051

Peterson, J., Dwyer, J., Adlercreutz, H., Scalbert, A., Jacques, P., \& McCullough, M. L. (2010). Dietary lignans: physiology and potential for cardiovascular disease risk reduction. Nutrition Review 68(10): 571-603 https://doi.org/10.1111/j.1753-4887.2010.00319.x

Reshma, M.V., Balachandran, C., Arumughan, C., Sunderasan, A., Sukumaran, D., Thomas, S. \& Saritha, S.S. 2010. Extraction, separation and characterisation of sesame oil lignan for nutraceutical applications. Food Chemistry 120: 1041 1046. https://doi.org/ 10.1016/j.foodchem.2009.11.047 
Ryan, E., Galvin, K., Connor, T. P. O., Maguire, A. R., \& O’Brien, N. M. (2006) Fatty acid profile, tocopherol, squalene and phytosterol content of brazil, pecan, pine, pistachio and cashew nuts. Int J Food Sci Nut, 57(34), 219-228. https://doi.org/10.1080/09637480410001725175

Ryan, E., Galvin, K., O’Connor, T.P., Maguire, A.R. \& O’Brien, N.M. 2007. Phytosterol, Squalene, Tocopherol Content and Fatty Acid Profile of Selected Seeds, Grains, and Legumes. Plant Foods Hum Nut, 62, 85-91. https://doi.org/10.1007/s11130-007-0046-8

Schwertner, H.A. \& Rios, D.C. (2012). Analysis of analysis of sesamin, asarinin, and sesamolin by HPLC with photodiode and fluorescent detection and by GC/MS: Application to sesame oil and serum samples. J Am Oil Chem Soc, 89, 1943-1950. https://doi.org/10.1007/s11746-012-2098-7

Uzun, B., Arslan, Ç. \& Furat, Ş. (2008). Variation in fatty acid compositions, oi content and oil yield in a germplasm collection of sesame (Sesamum Indicum L.). J Am Oil Chem Soc, 85(12), 1135-1142. https://doi.org/10.1007/s11746-008$\underline{1304-0}$

Virtanen, J.K., Wu, J.H.Y., Voutilainen, S., Mursu, J. \& Tuomainen, T.P. (2018) Serum n-6 polyunsaturated fatty acids and risk of death: the Kuopio Ischaemic heart disease risk factor study. Am J Clin Nut, 107(3): 427-435 https://doi.org/10.1093/ajcn/nqx063

Weiss, E.A. (2000). Oil Seed Crop (2nd ed.). USA.: Blackwell Longman Group Ltd.

Yamashita, K., Nohara, Y., Katayama, K. \& Namiki, M. 1992. Sesame seed lignans and gamma-tocopherol act synergistically to produce vitamin E activity in rats. J Nut, 122(12), 2440-2446. https://doi.org/10.1093/jn/122.12.2440

Zock, P.L., Vries, D. \& , \& Katan, M.B. (1994). Impact of myristic acid versus palmitic acid on serum lipid and lipoprotein levels in healthy women and men. Arteriosclerosis Thrombosis, 14, 567-575.

https://dx.doi.org/10.1161/01.ATV.14.4.567 